\title{
Diversity of hard tick populations and their geographic variations in northwestern Iran
}

\author{
Eslam Moradi- Asl ${ }^{1}$, Rohollah Moradi ${ }^{1}$, Zakiah Telmadarraiy ${ }^{1}$, Sayena Rafizadeh ${ }^{1}$, and \\ Yavar Rassi ${ }^{2}$ \\ ${ }^{1}$ Affiliation not available \\ ${ }^{2}$ 2. Department of Medical Entomology \& Vecotr Control, School of Public Health, Tehran \\ University of Medical Sciences, Tehran, Iran
}

September 11, 2020

\begin{abstract}
Abstract Ticks are forced vertebrate ectoparasites, including humans, and are vectors of serious diseases such as Crimean Congo Hemorrhagic Fever, Relapsing Fever, and various forms of encephalitis. Spatial assessment of the prevalence of ticks and detection of high risk areas for tick-borne disease transmission and evaluation of ecological measures are key aims of this research. Ticks were collected using standard methods From 27 villages in the region of Sarab County in north-eastern Iran during the four seasons of 2018-219 and identified using valid keys. The calculation of indices for biodiversity were based on the Margalf index, Shannon-Weiner index and Simpson index. R2.15 Statistical software was used for statistical analysis of indices of biodiversity, and ArcMap10.4.1 software and IDW and GeneralG methods and analysis were used to investigate spatial dispersion and to determine important tick hotspots. Thirty-five percent of the 2,500 animals surveyed were infected. A total of 1416 ticks were caught, $74.6 \%$ were adult ticks, \% were nymph and 1.4 percent were larvae. Ninety four percent of the ticks caught belonged to hard ticks relating to 4 genera and 6 percent to soft ticks relating to 2 genera. The highest species biodiversity was related to summer (1.4234), and the lowest was related to winter (0.7379), according to the Margalef diversity index. In the central part of the study region a large hotspot area was found. The area of study was very prone to tick-borne disease transmission in terms of tick diversity and tick species richness, and it was important to inform people to monitor to avoid diseases. Keywords: Ticks, Species biodiversity, GIS, Iran
\end{abstract}

\section{Introduction}

Ticks are the most important medical and veterinary ectoparasites and are one of the most important arthropod groups (Lane and Crosskey 2012). Ticks belong to the order of metastigmatia which feeds on animals and humans and play an important role in the transmission of the disease. This order is composed of two common argasidae and ixodidae families(Goodman et al 2005). There are about 899 hard tick species, and 185 soft tick species (de la Fuente 2018). In Iran there've been recorded of 14, 5, 8, 11, 1 and 3 hard tick species of Hyalomma ,Rhipicephalus, Ixodes, Haemaphysalis, Bophilus andDermacentor respectively. Ten percent of ticks feed on domestic animals, particularly cattle, sheep and goats. These are of major health significance due to the conditions that cause human and animal diseases (Rahbari et al 2007, Masoumi Asl et al 2009, Davari et al 2017 ).

Tick-borne diseases are among the most common emerging and re-emerging diseases in recent years that have spread to different geographic areas (de La Fuente et al 2017). Several diseases including tick-borne fever, Rocky Mountain spotted fever, Q fever, Lyme disease, and Crimean-Congo hemorrhagic fever (CCHF) are among the known tick-borne human diseases. (Nava et al 2009,Otranto et al 2014,Moradi Asl et al 2018 ) . 
Regardless of the importance of ticks in spreading different pathogens, its population structure, relative abundance and frequency, hosts type, habitats, ecology and diversity of species must be regulated. The study of tick biodiversity using various scientific indices seems to be very helpful in this regard (Masoumi Asl et al 2009, Wood and Lafferty 2013). The aims of this study was to determine the status of species diversity and richness of hard and soft ticks and their geographical distribution in the livestock of Sarab region in northwestern Iran using Simpson, Shannon Weiner and GIS software indicators.

\section{Materials and methods :}

2.1.Study area : Sarab s a county in East Azerbaijan Province in Iran. The capital of the county is Sarab. At the 2006 census, the county's population was 132,094, in 31,977 families. The county is subdivided into two districts: the Central District and Mehraban District. The county has four cities: Sarab, Mehraban, Sharabian, and Duzduzan. At the 2006 census, its population was 42,057, in 11,045 families. Livestock and animal husbandry have traditionally been common in most rural households.

\subsection{Tick collection :}

Twenty-seven villages were selected from a total of nine districts. Ten Locations were selected in each village (human, animal and livestock storage areas, traditional and modern grain deposits, farmland attached to the village and preferably attached to active livestock sables, estimated at 300 places in total.

During the study, 441000 cattle (331000 sheep and goats) and (95000 cows and oxen) (8000 horses) and (7000 donkeys) were in the Sarab county. Therefore, ticks from a total of 2,500 livestock were collected in this study, of which $75 \%$ of the sample size were sheep and goats, $23 \%$ were cows and oxen, and $2 \%$ were horses and donkeys. Valid keys were used to identify species of the ticks (Keirans and Litwak 1989, Gregory et al 1998). This experiment was carried out under the guidance of the Ethics Committee of the Tehran University of Medical Sciences (IR.TUMS.SPH.REC.1398.058).

\subsection{Biodiversity Indices}

Different indices of biodiversity were used in this study including species richness (Margalef's richness index), species diversity (Simpson's and Shannon Weiner's index).

\subsection{Calculation of tick dispersion}

Arcmap 10.4.1 software and interpolation with Inverse Distance Weighted (IDW) were used to analyze tick dispersion and to assess the distribution of disease vectors hot spots. The General G formula was used to determine the pattern of distribution of all Crimean Congo disease species and main vectors including Hyalomma marginatumand H.anatolicum in the study region.

$$
G=\frac{\sum_{i}^{N}=1 \sum_{j}^{N}=1 \mathrm{Wij} \mathrm{xixj}}{\sum_{i}^{N}=1 \sum_{j}^{N}=1 x i x j}, j \neq i
$$

\section{Results}

For a total of 2,500 animals examined, ticks infested 763 animals (30.5\%). A total of 300 stalls and stables were checked in 27 villages, 75 of which were infested with ticks (25\%). A total of 1,416 ticks have been collected, of which $30 \%$ were male, $44.6 \%$ were female, $22 \%$ were nymphs and $1.4 \%$ were also tick larvae. Of the $94 \%$ of the ticks collected, 11 species have been classified as hard ticks, belonging to 4 genera: Hyalomma (65\%), Heamiphysalis (11\%), Rhipicephalus (6\%), and Dermacenter (12\%). Three species of soft ticks from two genera of Ornithodorus and Argas were identified. (Table 1).

\begin{tabular}{|c|c|c|c|c|c|c|c|c|}
\hline otal & Larva & Nymph & Adult ticks & Adult ticks & Hosts & Hosts & Hosts & Hosts \\
\hline 46 & 0 & 0 & $\begin{array}{l}\text { Female } \\
33\end{array}$ & $\begin{array}{l}\text { Male } \\
13\end{array}$ & 0 & $\begin{array}{l}\text { Dor } \\
0\end{array}$ & $\begin{array}{l}\text { Sheep } \\
17\end{array}$ & $\begin{array}{l}\text { Cow } \\
11\end{array}$ \\
\hline
\end{tabular}




\begin{tabular}{|c|c|c|c|c|c|c|c|c|}
\hline Total & Larva & Nymph & Adult ticks & Adult ticks & Hosts & Hosts & Hosts & Hosts \\
\hline 319 & 0 & 2 & 111 & 206 & 0 & 12 & 69 & 52 \\
\hline 60 & 0 & 0 & 25 & 35 & 0 & 0 & 22 & 12 \\
\hline 143 & 0 & 0 & 141 & 2 & 0 & 2 & 67 & 39 \\
\hline 55 & 0 & 0 & 17 & 38 & 0 & 2 & 18 & 8 \\
\hline 18 & 18 & 0 & 0 & 0 & 0 & 0 & 2 & 0 \\
\hline 279 & 0 & 279 & 0 & 0 & 0 & 7 & 70 & 32 \\
\hline 104 & 0 & 0 & 87 & 17 & 0 & 0 & 65 & 4 \\
\hline 31 & 0 & 0 & 18 & 13 & 0 & 0 & 14 & 4 \\
\hline 23 & 0 & 0 & 23 & 0 & 0 & 0 & 19 & 0 \\
\hline 76 & 0 & 0 & 54 & 22 & 3 & 4 & 21 & 8 \\
\hline 20 & 0 & 0 & 10 & 10 & 0 & 0 & 6 & 8 \\
\hline 169 & 0 & 0 & 105 & 64 & 0 & 2 & 76 & 42 \\
\hline 520 & 0 & 434 & 65 & 21 & 63 & 0 & 42 & 0 \\
\hline 7 & 0 & 0 & 3 & 4 & 2 & 0 & 2 & 4 \\
\hline 42 & 0 & 29 & 13 & 0 & 7 & 0 & 0 & 0 \\
\hline 1912 & 18 & 744 & 705 & 445 & 75 & 29 & 510 & 224 \\
\hline
\end{tabular}

Table1. The total number of ticks collected from hosts and residential places in Sarab county,2018-19

Sheep and goats with $58.68 \%$, cows and ox with $13.23 \%$ and horses and donkeys with $2.14 \%$ respectively were the most infested animals with ticks. In terms of age, ticks were observed more in animals under 3 years of age $(49 \%)$ and the lowest infection $(10 \%)$ was observed in animals over 7 years of age, and the most infested section of the animals were sub-tail (29.89\%) and animal ears (25.69\%).

\subsection{Biodiversity and species richness}

Tick diversity and species richness were calculated on the basis of two factors: seasonal activity and host, the Margalf species richness index showed that the highest richness was related to summer (1.4234), and the lowest richness was related to winter (0.7379). The species diversity of ticks collected at different seasons in the research region was also significantly different $(\mathrm{P}<0.05)$.

The highest species diversity was related to summer (2.1709), and the lowest species diversity was related to winter (0.781), according to the Shannon-Wiener index measurements. The index of evennes of ticks collected during different seasons in the research region was significantly different $(\mathrm{P}<0.05)$. The evennes index analysis found that the highest uniformity was in relation to the summer season (0.9428) and the lowest uniformity was in relation to the autumn season (0.4428). The Simpson species diversity index also showed that the highest diversity was correlated with summer (0.8622), and the lowest diversity was associated with autumn (0.3549). The results of this study found that the species richness of ticks collected in the Sarab region during the first and second six months of the year had a significant difference $(\mathrm{P}<0.05)$, and the first six months of the year had higher and more diversity and richness of species than the second six months of the year (Table 2).

Table 2. Biodiversity and species richness of ticks captured in the studied areas of Sarab county, based on seasonal activity, 2018-2019

\begin{tabular}{lllll}
\hline & Spring & Summer & Fall & Winter \\
\hline Shannon-Wiener index & 2.1267 & 2.1709 & 0.7934 & 0.781 \\
Simpson's index)D( & 0.1449 & 0.1378 & 0.6451 & 0.6385 \\
Simpson's index(D-1) & 0.8551 & 0.8622 & 0.3549 & 0.3615 \\
Evennes Index & 0.9236161 & 0.942812 & 0.4428048 & 0.485265 \\
Margalef diversity index & 1.3702635 & 1.423474 & 0.8287641 & 0.7379352 \\
\hline
\end{tabular}


According to the Simpson Species Diversity Index, the findings of species diversity and richess based on different hosts showed that the highest species diversity among the studied hosts was correlated to sheep and goats (0.881), and the lowest species diversity was found in horses and donkeys (0.715). The highest species diversity was found in sheep and goats (2.333) and the lowest species diversity in horse and donkey hosts (1.399) according to the Shannon-Wiener index. There was a significant difference in the evenness index for livestock hosts that ranged from the highest for sheep and goats (0.9096) to the lowest for cows and ox (0.7945).(Table 3).

Table 3. Determining the diversity and species richness of ticks caught separately by the host in the study areas in Sarab county, 2018-2019

\begin{tabular}{lllll}
\hline & Cow \& Ox & Goat \&sheep & Donkey \&Horse & Stables \\
\hline Shannon-Wiener index & 1.905 & 2.333 & 1.399 & 0.447 \\
Simpson's index)D( & 0.198 & 0.119 & 0.285 & 0.787 \\
Simpson's index(D-1) & 0.802 & 0.881 & 0.715 & 0.213 \\
Evennes Index & 0.7945 & 0.9096 & 0.8693 & 0.3224 \\
Margalef diversity index & 1.807 & 1.708 & 1.077 & 0.483 \\
\hline
\end{tabular}

\subsection{Spatial distribution}

The most ticks were collected in the villages of Dozduzan 123 (6.43\%), Sharbian 120 (6.28\%), Mehraban 117 (6.12\%), Kelian 107 (5.6\%), Ardha 106 (5.54\%) and Mahin Bijand 101 (5.3\%) and the lowest in Dichan village $47(2.45 \%)$. In Mehraban district the highest spatial dispersion as well as the highest density of hard and soft tick species were found.

The findings of the interpolation study (IDW) revealed that there was a large hotspot area in the central part and a small hotspot in the northwestern part of the county of Sarab in terms of tick abundance, both of which were high-risk areas in the Mehraban region with 4596 and 1150 households in population. (Figure $1)$.

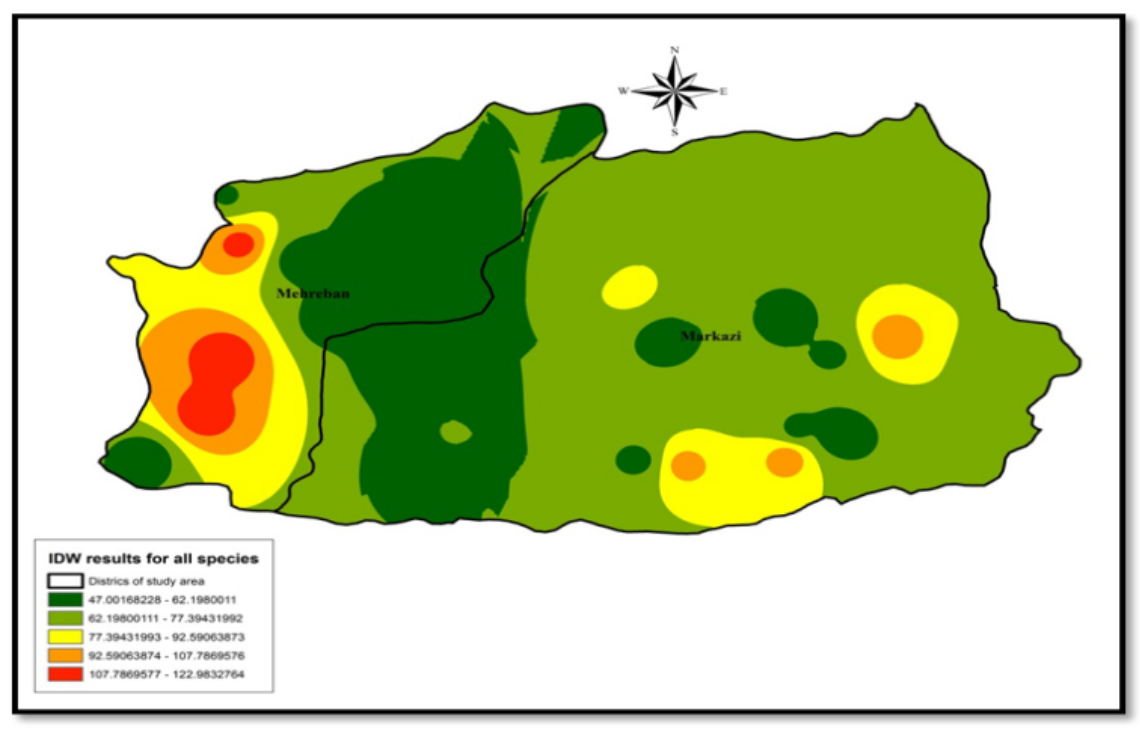

Figure 1. General distribution of ticks caught in the study areas of Sarab county,2018-2019

The results of the analysis of spatial distribution patterns for all species and for two species of H.marginatum 
andH.anatolicum using the General $\mathrm{G}$ index showed that all species were distributed randomly in all areas of study and did not have a specific pattern such as cluster or regular (Figure 2 and Table 4).

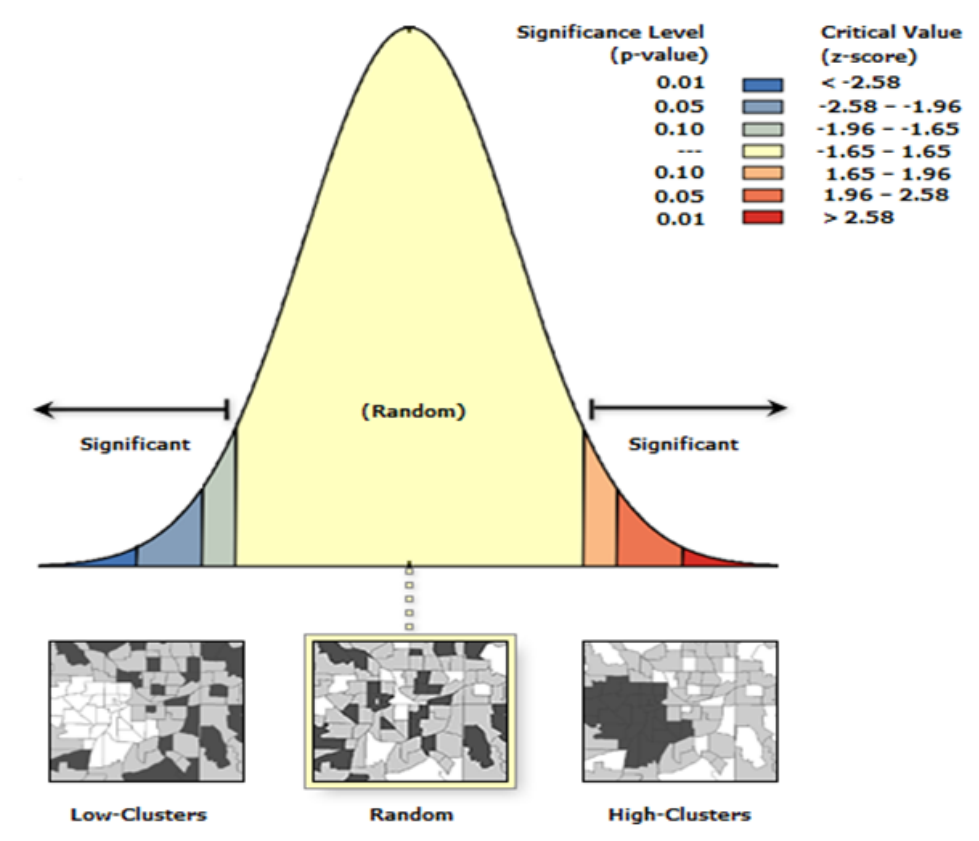

Figure 2. Results of scattering pattern analysis of ticks caught in Sarab county, East Azerbaijan, northwest of Iran, 2018-19

\begin{tabular}{lllll}
\hline General G Summary & General G Summary & General G Summary & Global Moran's I Summary & Global Moran's I Su \\
\hline Species & Observed General G & Expected General G & Variance & z-score \\
All species & 0.000015 & 0.000016 & 0.000000 & -0.357036 \\
Hyalomma marginatum & 0.000014 & 0.000016 & 0.000000 & -1.464457 \\
Hyalomma antalicum & 0.000013 & 0.000016 & 0.000000 & -0.911540 \\
\hline
\end{tabular}

Table 4. The results of hot-spot and autocorrelation analysis of tick species in Sarab county, East Azerbaijan, northwest of Iran, 2018-19

\section{Discussion}

In this study, 2,500 different livestock were studied and 30.5\% of livestock and $25 \%$ of stalls and stables were infested with different ticks, this is one of the first studies to include more samples and tick populations were also studied in Iran. In related surveys, the infection rate of ticks was 11\%, 9.37\%, $43 \%$ and $24 \%$ in northwest, west and north Iran (Salim Abadi et al 2011, Hashemi-Fesharaki et al 2011, Telmadarreyi 2010, Bakhshai et al 2012).

The highest frequency of captured ticks was related to spring $(37.24 \%)$ and the lowest frequency is related to winter $(11.83 \%)$ and this indicates the seasonal behavior of ticks in the mountainous and northwestern regions of Iran, mainly in spring, which can be attributed to the Nasiri study in Abdanan County, Ilam Province (Nasiri et al 2010). Nonetheless, more seasonal tick activity was recorded in summer and autumn in areas such as Golestan province northern Iran, which have ecologically different climates and have lower altitudes and higher temperatures than the mountainous areas (Sarani et al 2014). 
The highest tick infection was observed in sheep and goats in this research $(79.23 \%)$ and it was consistent with another study in the province of Ardabil, northwest Iran (Telmadarreyi 2010).

In the sample area, the tick biodiversity, according to the Shannon-Wiener index, was found to be moderate to high (2.432) and the biodiversity index of Simpson (D-1) was also determined to be 0,856 . The dominant species in the area therefore had a great diversity. We found the highest richness of ticks captured from cows and ox and the lowest from horses and donkeys, according to the Margalef species richness index. The findings of this research did not confirm previous studies in the province of Golestan (Sarani et al 2014) that found more sheep species compared to cows. The diversity of the species was highest in autumn, and lowest in winter. The findings of this research were consistent with study for seasonal ticks activities in northwestern Iran (Vatandoost et al 2012).

Six genera and 14 species of hard and soft ticks were collected in this research, of which the dominant genus was Hyalomma (48.12\%). The findings of this research revealed that the region was prone to diseases like Crimean Congo hemorrhagic fever. According to the study (2004) in the eastern province of Azarbaijan, northwestern Iran, the Hyalomma genus was confirmed to have the highest abundance (52.81 \%) which was consistent with recent study(unpublished data). Interestingly, in a survey conducted in West Azerbaijan province, 7 tick species with more abundant in the Hyalomma genus (unpublished data) were reported to have the highest abundance and distribution, as our recent research did. Based on the findings of this study and the above research, it can be inferred that the provinces located in northwestern Iran including East Azerbaijan, West Azerbaijan and Ardabil had a high abundance of Hyalomma species and were ecologically suitable habitat for this tick.

Identifying high-risk and low-risk disease and vector areas allows to make better decisions on the management of the vectors and diseases transmitted by them, and to arrange for the control and preventive management of the region. Throughout this research, the spreading of ticks as the vectors was found randomly around the region, but internal analysis revealed that the high-risk area of ticks was very high in the west of the study area as well as being a large hotspot. The high population of livestock and livestock occupation which have been the key hosts of ticks were some of the factors involved in this region. Therefore, in terms of tick-borne diseases, this area is indeed one of the high-risk areas and control measures should be taken to prevent bites of ticks and diseases that they transmit.

\section{Conclusion}

The findings of the recent study indicate that the number of tick species caught in this region is varied due to the large abundance of livestock in Sarab county and the wealth of animal and livestock husbandry practices and the production of dairy products. Because of the small scale of the county it reveals the richness of different species of ticks in this region. In the study of tick diversity in the research region among different hosts, it was observed that all the indices observed on sheep and goats have a comparatively higher value that the ticks are more associated with long hair hosts, so periodically picking the wool and hair of these hosts may be a way to reduce tick activity. Throughout this research, the spreading of ticks as the vectors was found randomly around the region, but internal analysis revealed that the high-risk area of ticks was very high in the west of the study area as well as being a large hotspot.

\section{Acknowledgements}

This study was financially supported by the Deputy of Research, Tehran University of Medical Sciences, Grant No. 40919.

\section{Conflict of interest}

There is no conflict of interest.

\section{Ethics statement}

This experiment was carried out under the guidance of the Ethics Committee of the Tehran University of Medical Sciences (IR.TUMS.SPH.REC.1398.058). 


\section{References}

1. Bakhshai, A., Jahani, Z., Askari, N., Etebar, F.,Ebrahimzade, E.(2012). Hard ticks fauna in the area of domestic ruminants and Kohnuj Jiroft, Kerman Province, Iran. Journal of Veterinary Laboratory Research, 4,145-149.

2.Davari, B., Alam, F.N., Nasirian, H., Nazari, M., Abdigoudarzi, M., Salehzadeh, A. (2017). Seasonal distribution and faunistic of ticks in the Alashtar county (Lorestan Province), Iran. The Pan African medical journal,27,284 doi: 10.11604/pamj.2017.27.284.10341

3.de la Fuente, J. (2018). Controlling ticks and tick-borne diseases... looking forward. Ticks and tick-borne diseases, 9,1354-7. doi: 10.1016/j.ttbdis.2018.04.001

4.de La Fuente, J., Antunes, S., Bonnet, S., Cabezas-Cruz, A., Domingos, A.G., Estrada-Peña, A., et al.(2017). Tick-pathogen interactions and vector competence: identification of molecular drivers for tickborne diseases. Frontiers in cellular and infection microbiology, 114, 1-13 doi.org/10.3389/fcimb.2017.00114

5.Goodman, J.L., Dennis, D.T., Sonenshine, D.E. (2005) Tick-borne diseases of humans: ASM press; Washington, DC, ISBN 1-55581-238-4.

6.Gregory, T., Felz, M.W., Durden, L.A.(1998). Identifying ticks: a pictorial guide. Patient Care ,32,172-3.

7. Hashemi-Fesharaki, R., Abdi-Goodarzi, M., Esmaeilnia, K.(2010). The photo guideline to identifying ticks (Ixodidae Family) in Iran. 1st. Tehran: Sooreh Publication,110.[in persian].

8.Keirans, J.E., Litwak, T.R.(1989). Pictorial key to the adults of hard ticks, family Ixodidae (Ixodida: Ixodoidea), east of the Mississippi River. Journal of Medical Entomology ,26,435-48. doi:10.1093/jmedent/26.5.435

9.Lane, R.P., Crosskey, R.W.(2012). Medical insects and arachnids: Springer Science \& Business Media; Springer Publication, UK.

10. Masoumi Asl, H., Goya, M. M., Vatandoost, H., Zahraei, S. M., Mafi, M., Asmar, M., Piazak, N., Aghighi, Z. (2009) The epidemiology of tick-borne relapsing fever in Iran during 1997-2006. Travel Medicine and Infectious Disease,7,160-4. doi: 10.1016/j.tmaid.2009.01.009

11.Moradi Asl, E., Vatandoos,t H., Telmadarreiy, Z., Mohebali, M., Abai, M.R.(2018). Repellency effect of flumethrin pour-on formulation against vectors of Crimean-Congo haemorrhagic fever. Eastern Mediterranean Health Journal,24,1082-7.

12. Nasiri, A., Telmadarraiy, Z., Vatandoost, H., Chinikar, S., Moradi, M., Oshaghi, M.A. (2010). Tick infestation rate of sheep and their distribution in Abdanan County, Ilam Province, Iran, 2007-2008. Iranian journal of arthropod-borne diseases, 4,56-60.

13.Nava ,S., Guglielmone, A.A., Mangold,A.J.(2009). An overview of systematics and evolution of ticks. Front Biosci (Landmark Ed), 14,2857-77

14. Otranto, D., Dantas-Torres, F., Giannelli ,A., Latrofa, M.S., Cascio, A., Cazzin, S., Ravagnan, S., Montarsi, F., Zanzani, S.A., Manfredi, M.T., Capelli, G.(2014). Ticks infesting humans in Italy and associated pathogens. Parasites \& vectors,328,1-9. doi: 10.1186/1756-3305-7-328.

15.Rahbari ,S., Nabian, S., Shayan, P. (2007). Primary report on distribution of tick fauna in Iran. Parasitology research,101,175-7. doi: 10.1007/s00436-007-0692-7

16. Salim Abadi, Y., Chinikar, S., Telmadarraiy, Z., Vatandoost, H., Moradi, M., Oshaghi, M. A., Ghiasi, M.(2011). Crimean-Congo hemorrhagic fever: a molecular survey on hard ticks (Ixodidae) in Yazd province, Iran. Asian Pacific journal of tropical medicine,4,61-3. doi: 10.1016/S1995-7645(11)60034-5

17. Sarani, M. , Telmadarraiyi, Z., SalahiMoghaddam, A., Azam ,K., Sedaghat, M. M.(2014). Distribution of ticks (Acari: Ixodidae) infesting domestic ruminants in mountainous areas of Golestan province, Iran . Asian Pac J Trop Biomed, 4,(Suppl 1),S246-251. doi: 10.12980/APJTB.4.2014C746 
18. Telmadarreyi, Z.(2010). Frequency of Ixodidae and Argasidae ticks and determination of their sensitivity in the toxin cypermetryn Meshkinshahr. Journal of Ardabil University of Medical Sciences,6,127-33. [in persian].

19. Vatandoost, H., Moradi Asl, E.,Telmadarreiy, Z., Mohebali, M., Masoumi Asl, H.,Abai, M. R., Zarei, Z. (2012). Field efficacy of flumethrin pour-on against livestock ticks in Iran. International Journal of Acarology , 457-464 .doi.org/10.1080/01647954.2012.662245

20.Wood, C.L., Lafferty, K.D.(2013) Biodiversity and disease: a synthesis of ecological perspectives on Lyme disease transmission. Trends in ecology \& evolution,28,239-47. doi: 10.1016/j.tree.2012.10.011.
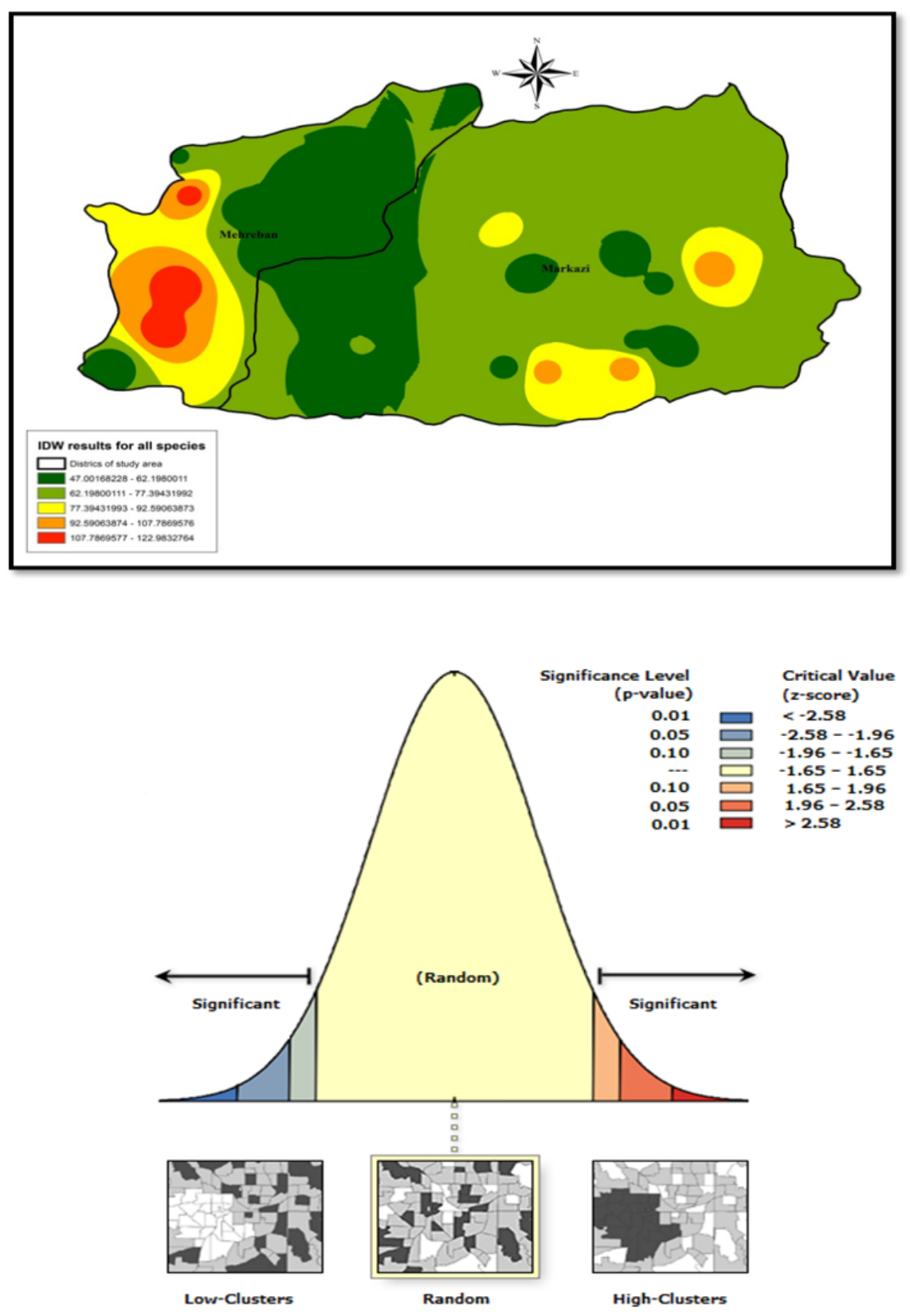


\section{Hosted file}

Table 1 Sarab.docx available at https://authorea.com/users/357558/articles/480059-diversityof-hard-tick-populations-and-their-geographic-variations-in-northwestern-iran

\section{Hosted file}

Table 2 Sarab.docx available at https://authorea.com/users/357558/articles/480059-diversityof-hard-tick-populations-and-their-geographic-variations-in-northwestern-iran

\section{Hosted file}

Table 3 Sarab.docx available at https://authorea.com/users/357558/articles/480059-diversityof-hard-tick-populations-and-their-geographic-variations-in-northwestern-iran

\section{Hosted file}

Table 4 Sarab.docx available at https://authorea.com/users/357558/articles/480059-diversityof-hard-tick-populations-and-their-geographic-variations-in-northwestern-iran 